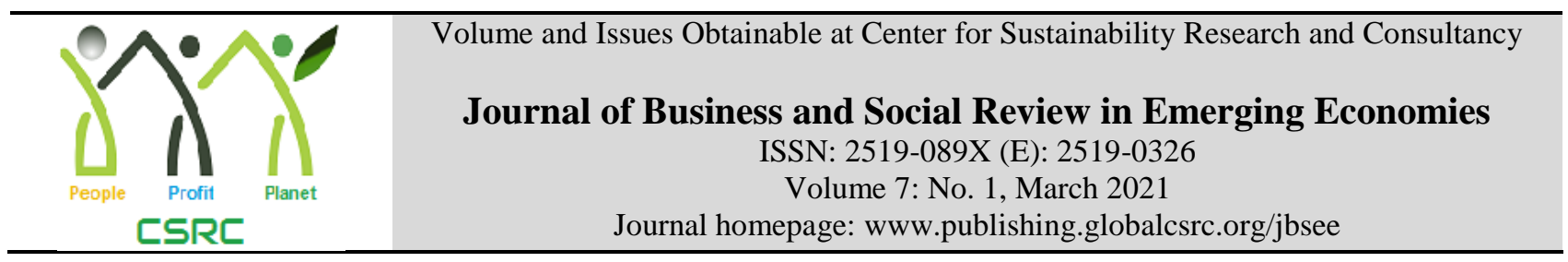

\title{
An Empirical Analysis to Understand Consumer Intention to Use Mobile Payment Platform: The Mediating Role of Trust
}

*Atif Ali Gill, Faculty Department of Business Administration, University of Sahiwal, Pakistan Riaz Hussain Ansari, Faculty Department of Business Administration, University of Sahiwal, Pakistan Zobia Malik, Ph.D. Scholar, Bahauddin Zakariya University, Multan, Pakistan

Muhammad Waseem Tufail, Department of Applied Psychology, University of Sahiwal, Pakistan

*Corresponding author's email address: atifali@uosahiwal.edu.pk

\section{ARTICLE DETAILS ABSTRACT}

\section{History}

Revised format: Feb 2021

Available Online: Mar 2021

\section{Keywords}

Mobile payment channel, Mobility, Customization, Technical Security, Trust.

JEL Classification:

$M O, M 1$ role.
Purpose: Money transfer through third-party mobile payment platforms has become common nowadays in western countries. While in developing countries, the adoption of mobile payment channels still at the infancy stage. The current study based on diffusion of innovation theory investigates the antecedents of intention to use mobile payment channels through trust's mediating

Methodology: The survey method was used to collect data from the 250 consumers using the mobile payments services of JazzCash and Easypaisa in Pakistan. Partial least square structural equation modeling (PLS-SEM) technique employed to test the collected data statistically.

Findings: Results found the significant impact of mobility, customization, and security on trust that intends to utilize mobilepayment channels.

Implications: The current study's findings provide guidelines to the administration of mobile payment systems to improve security features, mobility, and customization that wins customers' trust and is inclined to use mobile payment platform. of Trust. Journal of Business and Social Review in Emerging Economies, 7(1), 209-217.

\section{Introduction}

The mobile technology advancement has revolutionized the business across the world, including payment channels (Gong et al., 2020). Mobile payment methods (m-payment) have gained much popularity in developed countries (Pal et al., 2020). The consumer can use m-payment channels to execute several types of business transactions without time and location using online through internet technology and offline by utilizing messaging service (Park et al., 2019). The m-payment system provides an alternative to local consumers using traditional cash-based banking channels to carry out 
their day-to-day financial transactions (Cao et al., 2018).

According to the State bank of Pakistan annual performance review report (2017), Pakistan is rapidly adopting the digital modes of payment with the increasing number of electronic transactions $17 \%$ year on year growth. Total 625.8 million transactions via electronic payment channels worth 37.1 trillion in 2017, which witnessed considerable growth in digital mobile payment channels. World Bank has reported that about 100 million adults have no access to traditional banking channels due to remote areas and lack of infrastructure, creating a huge opportunity to provide branchless banking channels through mobile payment platforms. Easypaisa, launched in 2009 by Telenor Pakistan and Tameer Microfinance Bank, is a mobile payment platform that provides services across Pakistan. JazzCash is a digital mobile payment gateway formerly known as MobiCash launched in 2012 by Mobilink in partnership with Mobilink Microfinance bank, the services of JazzCash also widely available across Pakistan. The current study considered these top two m-payment channels to investigate the factors affecting the intention to use m-payment platforms in Pakistan. Despite the increase in digital technology and m-payment channels, consumers' intention to use is usually low (Kemal, 2019).

Previous studies stated trust as a significant antecedent of consumer acceptance toward new technology like m-payment methods (Cao et al., 2018; Gong et al., 2020; Shen et al., 2017). Institutions need to build trust in customers to use m-payments. Many customers keep away from the m-payment system because of trust issues, and they prefer traditional methods. Most of the studies examined trust with the combination of other constructs conducted in western countries. There is a dearth of study in developing countries like Pakistan (Farah et al., 2018).

The objectives of the current study are twofold. First, this study intends to examine the determinants that build customer's trust in m-payments platforms in Pakistan. Second, this study investigates the mediating impact of trust between key antecedents and intentions to use m-payment platforms. The research findings theoretically contribute to the existing literature by extending the diffusion of innovation (DOI) theory and providing guidelines to the policymakers to develop better m-payment platforms for better customer usage.

\section{Literature Review}

\section{Mobility and Trust in the Mobile Payment Platform}

Trust is a social phenomenon representing individual faith in the third party's performance with due diligence and integrity(Cao et al., 2018). With the increase in electronic financial transactions, researchers continuously investigate the determinants that build customer trust towards a digital payment channel. 'Reliability' and 'Technical features' are major factors to build customer's trust towards mpayments. Other studies found that flexibility and convenience also significantly impact customer digital payment requirements that enhance their trust towards a digital platform (de Luna et al., 2019; Kleivene, 2018). Mobility is to use m-payments without any restriction of time and location. Mobility facilitates consumers to access online financial transactions through mobiles, enhancing their trust towards mpayment channels. The following hypothesis can be proposed:

H1: Mobility has a significant influence on trust in the mobile payment platform.

\section{Customization and Trust in the Mobile Payment Platform}

Customization is a feature of m-payment that reflects the advantages of third-party m-payment platforms (Raman \& Aashish, 2021). It happens to have major control over their decisions, whether to use an mpayment system or not. In m-payment services, major security customization is delivered where consumers can upgrade users' security accounts by adjusting their security settings. Customize security setting is a method to influence security conduct in m-payment services. Hence this research attitude user's security conducts by checking their customization behaviours in the security setting. JazzCash and 
Easy paisa users can change the home page at their convenience by selecting their favourite software, building trust among consumers (Acheampong et al., 2021). Those mentioned above proposed the following hypothesis:

$\mathrm{H} 2$ : Customization has a significant influence on the trust in the mobile payment platform.

\section{Technical Security and Trust in the Mobile Payment Platform}

Security is the topmost concern for customers when it comes to making mobile financial payments (Park et al., 2019). Customers feel risks such as loss of personal data, information, money, account details, and unauthorized access to the system. Security is essential in the m-payment channel so that consumers believe their assets and personal information remain confidential and secure while executing transactions over the internet. Online transactions involve sharing details of the account and other private consumer data, making people very cautious about using the m-payment channel (S. Singh \& Srivastava, 2018). Online mobile payments require high-end security. Customers trust in highly secured m-payment channels (Cao et al., 2018). The above-stated postulated the following hypothesis:

H3: Technical Security has a significant influence on the trust in mobile payment platform.

\section{Trust and Intention to Use Mobile Payment Platform}

Continuance intention is a customer's inclination to use or refuse a system continuously. Trust is the customer's confidence in m-payment usage (Liébana-Cabanillas et al., 2020). Trust has a significant influence on continuance intention for mobile payment customers. Trust influences customers' continuance intention towards m-payments. It focal on trust build progress and raises the significance of trust towards continuance (Shao et al., 2019). Customers' trust is positively associated with continuance intention. Consumers with strong confidence and trust in a particular system are inclined to use that system for a longer period (Merhi et al., 2019). As mentioned earlier, postulated the following hypothesis:

H4: Trust has a significant influence on the intention to use the mobile payment platform.

\section{The Mediating Role of Trust}

Trust has been indicated as a derivate construct influenced by the antecedents of mobility, customization, and technical security that reflect the quality factors of mobile payment channels that affect the continuance intention of using the m-payment channel (Shao et al., 2019; N. Singh \& Sinha, 2020). Trust has been examined as an intermediate variable that reflects the indirect effect of antecedent constructs. The following hypotheses can be stated as follows:

H5: Trust mediates the relationship between mobility and intention to use the mobile payment platform.

H6: Trust mediates the relationship between customization and intention to use the mobile payment platform.

H7: Trust mediates the relationship between technical security and the intention to use the mobile payment platform.

\section{Diffusion of Innovation (DOI) Theory}

According to the Diffusion of Innovation (DOI) theory, an individual adopts a technology due to its attributes (Min et al., 2019). Diffusion reflects the penetration of innovation over time through different channels of the communication process among societal members (Lee et al., 2019). DOI has been witnessed in numerous studies related to information systems and technology adoption. Relative advantage is considered a predictor in DOI theory that reflects the customer preference of new technology over old methods like m-payment platforms mobility and customization has cognitive appeal to the consumers over the traditional payment channels (Lee et al., 2019; Shao et al., 2019). The technical attribute in current research refers to the security features of m-payment platforms that ensure 
that customers' transactions are technically safe and reliable. Based on research gaps in the literature mentioned above and the underpinning theory of DOI following theoretical framework has been proposed, as shown in Figure 1.

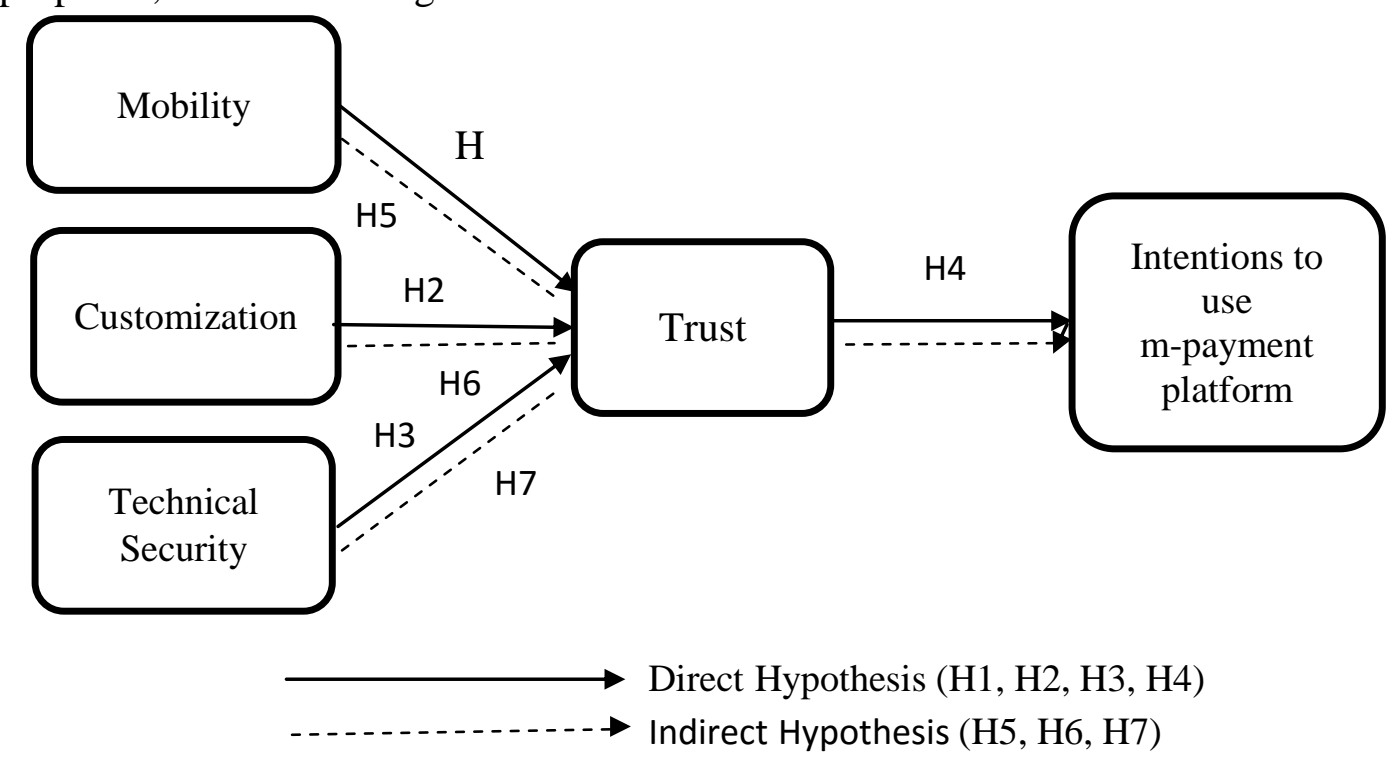

Figure 1. Theoretical Framework

\section{Methodology}

\section{Research Setting and Collection of Data}

A survey method through a close-ended questionnaire was used to collect data from the customers' experience of using two leading m-payment platforms JazzCash and Easypaisa, in Pakistan. Hence, Purposive sampling was applied. 85 sample size is sufficient, calculated through G*POWER software with the settings of 0.15 for effect size, 0.05 for error Type I, and $80 \%$ power. However, considering the low response rate in Pakistan, 400 questionnaires were distributed among the respondents where only 230 were returned. Eighteen questionnaires were omitted from the final analysis due to incomplete and missing data. Table 1 described the demographic characteristics of the overall sample.

\section{Measures}

The items used to measure the constructs of the present study adopted from previous literature. A 5point Likert scale was deployed to gauge all items where "1" represents the strongly disagree, and "5" denotes the strongly agree.

\section{Statistical Tool for Data Analysis}

The partial least squares structural equation modeling (PLS-SEM) technique was to analyze the data. The SmartPLS 3.0 software was used to assess the hypotheses statistically. The current study applied the bootstrapping procedure to assess the developed hypotheses, and normalization of data is not a prerequisite in PLS-SEM. It relies on bootstrapping for checking the significance of path coefficients and mediation analysis.

\section{Data Analysis and Results Demographic Data}

Respondents' demographic data in Table 1 depicted that males (56\%) and females (44\%) participated in the study. The age variable results revealed that most users are within the age bracket of 23-30 years (35\%). The occupation variable reflected that most of the respondents were an employee (49\%) of the total sample. The monthly use frequency data stated the $44 \%$ of respondents used mobile payment channels 11-20 times in a month.

Table 1: Respondent profile

\begin{tabular}{|c|c|c|}
\hline Demographic variables & Frequency & Percent $(\%)$ \\
\hline
\end{tabular}




\begin{tabular}{lll}
\hline Gender & 112 & $56 \%$ \\
Male & 88 & $44 \%$ \\
Female & & \\
Age & 67 & $33.5 \%$ \\
Less than 23 years & 70 & $35 \%$ \\
$23-30$ years & 40 & $20 \%$ \\
31-40 years & 23 & $11.5 \%$ \\
More than 40 years & & \\
Occupation & 56 & $28 \%$ \\
Students & 98 & $49 \%$ \\
Employee & 46 & $23 \%$ \\
Others & & \\
Monthly use frequency & 78 & $39 \%$ \\
1-10 times & 88 & $44 \%$ \\
$11-20$ times & 19 & $9.5 \%$ \\
$21-30$ times & 15 & $7.5 \%$ \\
$>31$ times & & \\
\hline
\end{tabular}

\section{Measurement Model Assessment}

The measurement model used to assess the present study's reliability and validity using the approach recommended for reflective constructs (Hair et al., 2017). The results of the measurement model are depicted in Table 2. The numbers show that the items are well-developed and valid for further statistical analysis.

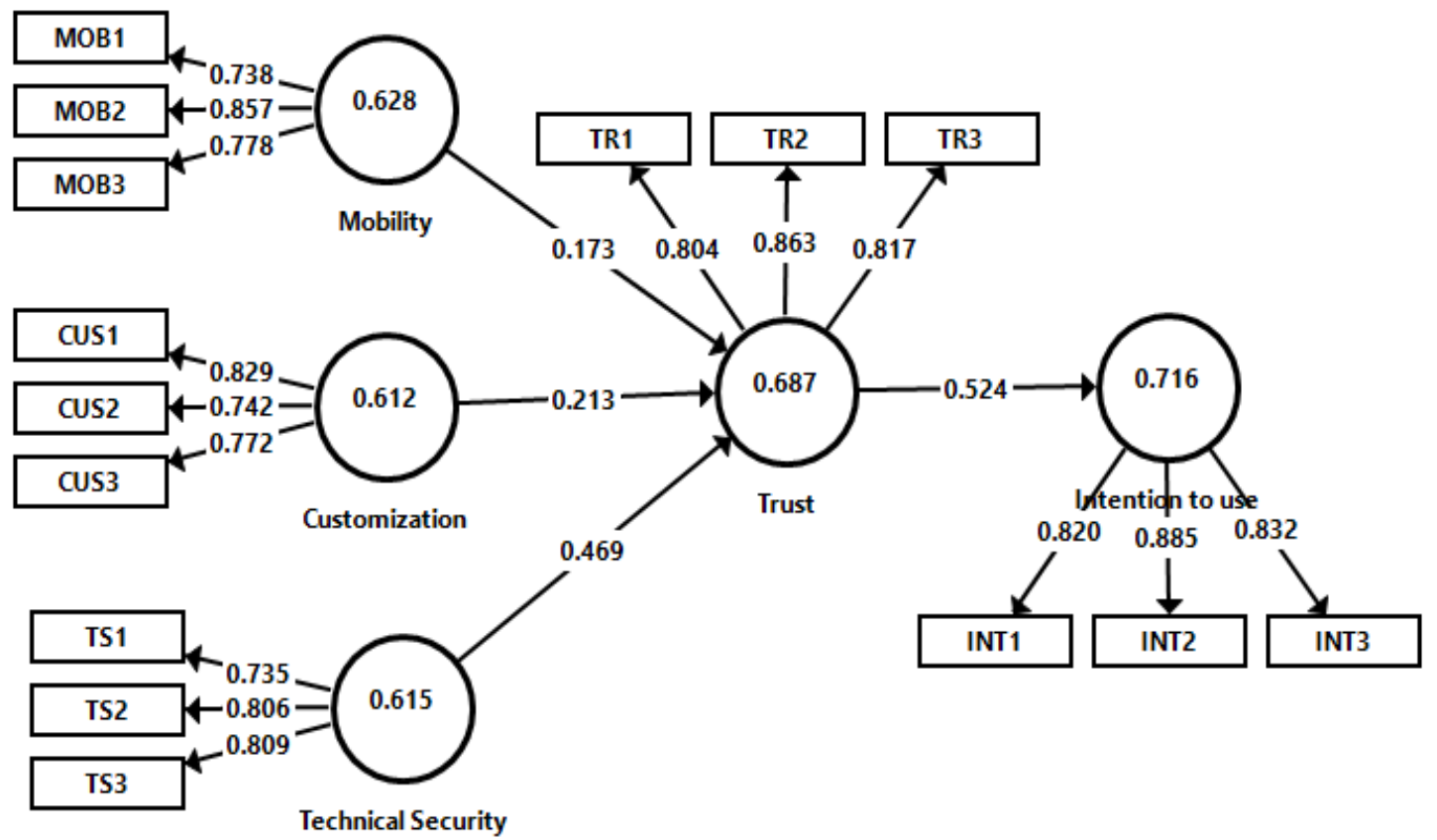

Figure 2: Measurement Model

\section{Internal Consistency, Reliability, and Convergent Validity}

Internal consistency measured through loadings of items all constructs were reflective and loadings values are greater than 0.7, showing all items' internal consistency (Hair Jr et al., 2020). The reliability of constructs measured through composite reliability and all values in Table 2 are greater than 0.7 shows that all constructs are reliable (Hair et al., 2014). The average variance extracted (AVE) was used to measure the convergent validity of the constructs employed in the present study. All construct AVE values are greater than 0.5 in Table 2 that revealed that all constructs are convergent valid.

Table 2: Internal consistency, reliability and convergent validity

\begin{tabular}{lllll}
\hline Constructs & Items & Loading & CR & AVE \\
\hline Mobility & MOB1 & 0.738 & 0.835 & 0.628 \\
\hline
\end{tabular}




\begin{tabular}{lllll}
\hline & MOB2 & 0.857 & & \\
MOB3 & 0.778 & 0.612 \\
Customization & CUS1 & 0.829 & 0.825 & \\
Technical Security & CUS3 & 0.742 & & 0.615 \\
& TS1 & 0.735 & 0.827 & \\
Trust & TS2 & 0.806 & & 0.687 \\
& TS3 & 0.809 & & \\
Intention to use & TR1 & 0.804 & 0.868 & 0.716 \\
& TR2 & 0.863 & & \\
\hline
\end{tabular}

Note: $\mathrm{CR}=$ Composite reliability, $\mathrm{AVE}=$ Avergae variance extracted

\section{Discriminant Validity}

Discriminant validity was measured using the Fornell \& Larcker (1981) method stated that all diagonal values should be higher than corresponding correlational values. Table 3 revealed that all the present study constructs (Mobility, Customization, Technical Security, Trust, and Intention to use) were discriminant valid as all diagonal values $(0.782,0.846,0.793,0.784$ and 0.829$)$ were higher than others corresponding values as shown in Table 3.

Table 3

Respondent profile

\begin{tabular}{llllll}
\hline Constructs & $\mathbf{1}$ & $\mathbf{2}$ & $\mathbf{3}$ & $\mathbf{4}$ & $\mathbf{5}$ \\
\hline CUS (1) & $\mathbf{0 . 7 8 2}$ & & & & \\
INT (2) & 0.592 & $\mathbf{0 . 8 4 6}$ & & & \\
MOB (3) & 0.690 & 0.621 & $\mathbf{0 . 7 9 3}$ & & \\
TS (4) & 0.643 & 0.548 & 0.693 & $\mathbf{0 . 7 8 4}$ & $\mathbf{0 . 8 2 9}$ \\
TR (5) & 0.634 & 0.524 & 0.645 & 0.726 &
\end{tabular}

Note: $\mathrm{CUS}=$ customization, INT= Intention to use, $\mathrm{MOB}=$ mobility, TS=Technical Security, TR=Trust

\section{Structural Model Assessment}

After measuring the construct's reliability and validity through the measurement model, the following procedure is bootstrapping through SmartPLS (Preacher \& Hayes, 2008). The inner model, also known as the structural model, indicates the significance of relationships between constructs. The structural model is present in Figure 3. 


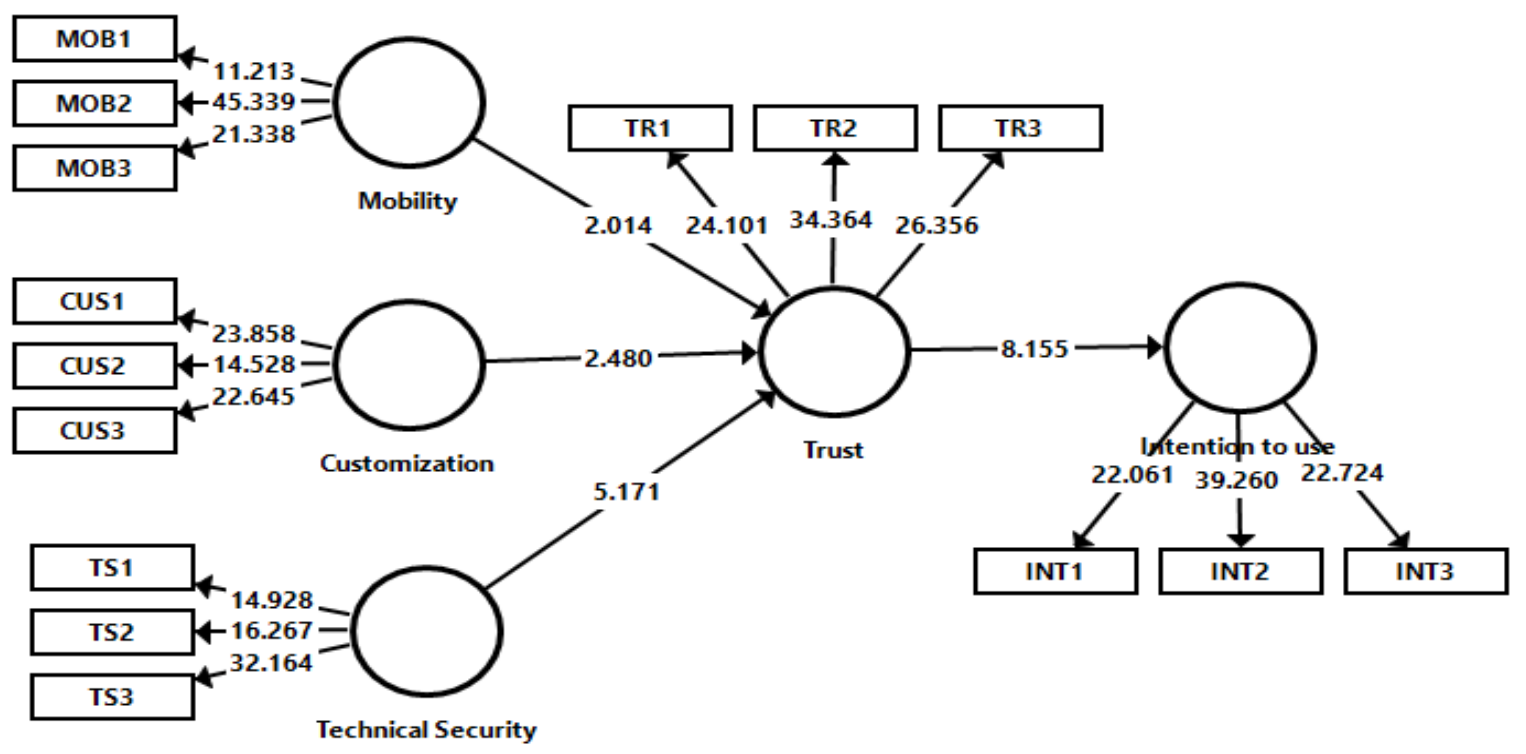

Figure 3: Structural Model

\section{Direct Relationships analysis}

The structural model measures the significance of the relationship between exogenous and endogenous variables of the study. Path coefficient and t-values were assessed to evaluate the structural model. Pvalue less than 0.05 indicated the acceptance of the proposed hypothesis. Table 4 represented the general structural model assessment results of direct effects hypotheses, and all four hypotheses H1, H2, H3 and H4 were supported.

Table 4: Respondent Profile

\begin{tabular}{lllllllll}
\hline Hypothesis & Relationships & Std. Beta & Std. Error & T-Value & P-Value & Decision & $\mathbf{R}^{2}$ & $\mathbf{f}^{\mathbf{2}}$ \\
\hline H1 & MOB-> TR & 0.173 & 0.086 & 2.014 & 0.045 & Supported & 0.581 & 0.030 \\
H2 & CUS-> TR & 0.213 & 0.086 & 2.480 & 0.013 & Supported & & 0.052 \\
H3 & TS-> TR & 0.469 & 0.091 & 5.171 & 0.000 & Supported & 0.249 \\
H4 & TR-> INT & 0.524 & 0.064 & 8.155 & 0.000 & Supported & 0.271 & 0.379 \\
\hline
\end{tabular}

Note: CUS=customization, INT= Intention to use, MOB=mobility, TS=Technical Security, TR=Trust

\subsubsection{Mediation Analysis}

Mediation analysis in the current study was performed using bootstrapping method (Hair Jr et al., 2020; Preacher \& Hayes, 2008). There were three indirect hypotheses H5, H6, and H7. Results in Table 5 show that $\mathrm{H} 6$ and $\mathrm{H} 7$ were supported. While H5 was not supported, showing zero straddled between upper limit $97.50 \%$ and lower limit $2.50 \%$ and p-value greater than 0.05 .

Table 5: Respondent Profile

\begin{tabular}{lllllllll}
\hline $\begin{array}{l}\text { Hypothe } \\
\text { sis }\end{array}$ & Relationships & $\begin{array}{l}\text { Std. } \\
\text { Beta }\end{array}$ & Std. Error & T- Value & $\begin{array}{l}\text { P- } \\
\text { Value }\end{array}$ & $\mathbf{2 . 5 0 \%}$ & $\mathbf{9 7 . 5 0 \%}$ & Decision \\
\hline H5 & MOB $>$ TR $>$ INT & 0.091 & 0.049 & 1.864 & 0.063 & -0.013 & 0.198 & Not Supported \\
H6 & CUS > TR > INT & 0.112 & 0.052 & 2.146 & 0.032 & 0.027 & 0.217 & Supported \\
H7 & TS > TR > INT & 0.246 & 0.053 & 4.606 & 0.000 & 0.156 & 0.347 & Supported \\
\hline
\end{tabular}

Note: $\mathrm{CUS}=$ customization, INT= Intention to use, $\mathrm{MOB}=$ mobility, TS=Technical Security, TR=Trust

\section{Discussion and Conclusion}

The current study utilizes diffusion of innovation (DOI) theory to analyze the indirect effect of mobility, customization, and technical security intention to use m-payment platform through trust. There were seven hypotheses, of which four were direct. Three were indirect hypotheses that measure the mediating impact of trust between antecedents and intention to use the m-payment channel. The present study results revealed that m-payment services' mobility has a significant positive influence on customers' trust who use the m-payment portal. Literature also supported the same results (Merhi et al., 2019; N. Singh 
\& Sinha, 2020). Results depicted that m-payment services' security significantly influences customers' trust using m-payment portal, consistent with the previous studies. Customization also revealed as a significant predictor of the trust that led to intention to use the m-payment portal. The outcome of the current hypothesis result is consistent with the previous scholarly work. The mediation hypotheses result revealed that trust did not mediate the relationship between mobility and intention to use the m-payment channel that may be due to study conducted in developing country context where mobility is more important to users for intention to use m-payment channels and trust has no much weightage in case of mobility (Lee et al., 2019). Other mediation hypotheses were supported that trust mediates positively between customization, technical security and intention to use m-payment portal supported through literature (Cao et al., 2018; Shao et al., 2019).

The present study has several implications. First, the extension of DOI theory by the mediation of trust and providing key determinants of trust leads to higher intention to use the m-payment platform. Second, the present study considers mobility and customization were providing key elements for the relative advantage that build customers' trust, which facilitates intention to use the m-payment platform. The current study provides certain practical contributions for m-payment platform administrators, especially from a developing country perspective. First, m-payment platforms like JazzCash and Easypaisa should customize their applications according to customers' needs to feel easy and flexible to use. Second, technical security should be enhanced by two-step verification and end-to-end encryption that builds customer trust and improves their continuance intention.

\section{Limitations and Future Research Directions}

Based on the diffusion of innovation theory present study examine the key determinants of the trustbuilding framework that leads toward intention to use the m-payment platform. Empirical results depict that mobility, customization, and technical security are vital to enhancing customers' trust, improving intention to use the m-payment platform. Current research has several limitations and future research directions. The first constraint is data collected from consumers using JazzCash and Easypaisa. In the future, more mobile payment gateways can be included, like Upaisa. Current research examines the mediating impact of trust, in the future moderating effect of customer gender, age, and experience can be incorporated for more in-depth findings of behavioural differences. The current study examines the $\mathrm{m}$ payment users in Pakistan, while future studies may conduct a different country to test the proposed theoretical framework's generalizability.

\section{References:}

Acheampong, P., Boamah, K. B., Agyeman-Prempeh, N., Boateng, F., Bediako, I. A., \& Abubakar, R. (2021). Trust and Continuance of Mobile Payment Use Intention: A Study Based on Structural Equation Modeling. Information Resources Management Journal (IRMJ), 34(1), 19-42.

Cao, X., Yu, L., Liu, Z., Gong, M., \& Adeel, L. (2018). Understanding mobile payment users' continuance intention: A trust transfer perspective. Internet Research.

de Luna, I. R., Liébana-Cabanillas, F., Sánchez-Fernández, J., \& Muñoz-Leiva, F. (2019). Mobile payment is not all the same: The adoption of mobile payment systems depending on the technology applied. Technological Forecasting and Social Change, 146, 931-944.

Farah, M. F., Hasni, M. J. S., \& Abbas, A. K. (2018). Mobile-banking adoption: Empirical evidence from the banking sector in Pakistan. International Journal of Bank Marketing.

Fornell, C., \& Larcker, D. F. (1981). Evaluating structural equation models with unobservable variables and measurement error. Journal of Marketing Research, 39-50.

Gong, X., Zhang, K. Z., Chen, C., Cheung, C. M., \& Lee, M. K. (2020). What drives trust transfer from web to mobile payment services? The dual effects of perceived entitativity. Information \& Management, 57(7), 103250.

Hair, Hult, G. T. M., Ringle, C., \& Sarstedt, M. (2014). A primer on partial least squares structural equation modeling (PLS-SEM). 
Hair, J., Hollingsworth, C. L., Randolph, A. B., \& Chong, A. Y. L. (2017). An updated and expanded assessment of PLS-SEM in information systems research. Industrial Management \& Data Systems, 117(3), 442-458. https://doi.org/10.1108/IMDS-04-2016-0130

Hair Jr, J. F., Howard, M. C., \& Nitzl, C. (2020). Assessing measurement model quality in PLS-SEM using confirmatory composite analysis. Journal of Business Research, 109, 101-110.

Kemal, A. A. (2019). Mobile banking in the government-to-person payment sector for financial inclusion in Pakistan. Information Technology for Development, 25(3), 475-502.

Kleivene, L. E. (2018). P2P Mobile Payments: Investigating the Factors of Adoption Among Students in Germany. In Omnichannel Branding (pp. 45-67). Springer.

Lee, J., Ryu, M. H., \& Lee, D. (2019). A study on the reciprocal relationship between user perception and retailer perception on platform-based mobile payment service. Journal of Retailing and Consumer Services, 48, 7-15.

Liébana-Cabanillas, F., Japutra, A., Molinillo, S., Singh, N., \& Sinha, N. (2020). Assessment of mobile technology use in the emerging market: Analyzing intention to use m-payment services in India. Telecommunications Policy, 44(9), 102009.

Merhi, M., Hone, K., \& Tarhini, A. (2019). A cross-cultural study of the intention to use mobile banking between Lebanese and British consumers: Extending UTAUT2 with security, privacy and trust. Technology in Society, 59, 101151.

Min, S., So, K. K. F., \& Jeong, M. (2019). Consumer adoption of the Uber mobile application: Insights from diffusion of innovation theory and technology acceptance model. Journal of Travel \& Tourism Marketing, 36(7), 770-783.

Pal, A., Herath, T., De', R., \& Rao, H. R. (2020). Contextual facilitators and barriers influencing the continued use of mobile payment services in a developing country: Insights from adopters in India. Information Technology for Development, 26(2), 394-420.

Park, J., Amendah, E., Lee, Y., \& Hyun, H. (2019). M-payment service: Interplay of perceived risk, benefit, and trust in service adoption. Human Factors and Ergonomics in Manufacturing \& Service Industries, 29(1), 31-43.

Preacher, K. J., \& Hayes, A. F. (2008). Asymptotic and resampling strategies for assessing and comparing indirect effects in multiple mediator models. Behavior Research Methods, 40(3), 879-891. https://doi.org/10.3758/BRM.40.3.879

Raman, P., \& Aashish, K. (2021). To continue or not to continue: A structural analysis of antecedents of mobile payment systems in India. International Journal of Bank Marketing.

Shao, Z., Zhang, L., Li, X., \& Guo, Y. (2019). Antecedents of trust and continuance intention in mobile payment platforms: The moderating effect of gender. Electronic Commerce Research and Applications, 33, 100823.

Shen, H., Liu, P., \& Yi, S. (2017). Trust transfer mechanism and intention on accepting NFC mobile payment: An empirical research. In Advances in human factors and system interactions (pp. 363376). Springer.

Singh, N., \& Sinha, N. (2020). How perceived trust mediates merchant's intention to use a mobile wallet technology. Journal of Retailing and Consumer Services, 52, 101894.

Singh, S., \& Srivastava, R. (2018). Predicting the intention to use mobile banking in India. International Journal of Bank Marketing. 